\title{
A Review of Optimization Algorithms in Solving Hydro Generation Scheduling Problems
}

\author{
Ali Thaeer Hammid 1,2(D, Omar I. Awad ${ }^{3}{ }^{-}$, Mohd Herwan Sulaiman ${ }^{2}$, \\ Saraswathy Shamini Gunasekaran ${ }^{4}$, Salama A. Mostafa ${ }^{5, * \mathbb{C}}$, Nallapaneni Manoj Kumar ${ }^{6, *(\mathbb{D} \text {, }}$ \\ Bashar Ahmad Khalaf ${ }^{7}$, Yasir Amer Al-Jawhar ${ }^{8,9}$ and Raed Abdulkareem Abdulhasan ${ }^{8}$ \\ 1 Computer Engineering Techniques Department, Faculty of Information Technology, Imam Ja'afar Al-Sadiq \\ University, Baghdad 10012, Iraq; ali.thaeer.hammid@gmail.com \\ 2 Faculty of Electrical and Electronics Engineering, Universiti Malaysia Pahang, Pahang, \\ Pekan 26600, Malaysia; herwan@ump.edu.my \\ 3 State Key Laboratory of Automotive Safety and Energy, Tsinghua University, Beijing 100084, China; \\ omaribr78@gmail.com \\ 4 College of Computing and Informatics, Universiti Tenaga Nasional, Selangor, Kajang 43000, Malaysia; \\ sshamini@uniten.edu.my \\ 5 Faculty of Computer Science and Information Technology, Universiti Tun Hussein Onn Malaysia, Johor, \\ Batu Pahat 86400, Malaysia \\ 6 School of Energy and Environment, City University of Hong Kong, Kowloon, Hong Kong, China \\ 7 College of Basic Education, University of Diyala, Diyala 32001, Iraq; basharalzubaidy60@gmail.com \\ 8 Faculty of Electrical and Electronic Engineering, Universiti Tun Hussein Onn Malaysia, Johor, \\ Batu Pahat 86400, Malaysia; yasir.jawhar@ieee.org (Y.A.A.-J.); raadabd39@gmail.com (R.A.A.) \\ 9 Iraqi Ministry of Communications (M.O.C.), Mamoon, Baghdad 10012, Iraq \\ * Correspondence: salama@uthm.edu.my (S.A.M.); mnallapan2-c@my.city.edu.hk or \\ nallapanenichow@gmail.com (N.M.K.)
}

Received: 19 April 2020; Accepted: 25 May 2020; Published: 1 June 2020

\begin{abstract}
The optimal generation scheduling (OGS) of hydropower units holds an important position in electric power systems, which is significantly investigated as a research issue. Hydropower has a slight social and ecological effect when compared with other types of sustainable power source. The target of long-, mid-, and short-term hydro scheduling (LMSTHS) problems is to optimize the power generation schedule of the accessible hydropower units, which generate maximum energy by utilizing the available potential during a specific period. Numerous traditional optimization procedures are first presented for making a solution to the LMSTHS problem. Lately, various optimization approaches, which have been assigned as a procedure based on experiences, have been executed to get the optimal solution of the generation scheduling of hydro systems. This article offers a complete survey of the implementation of various methods to get the OGS of hydro systems by examining the executed methods from various perspectives. Optimal solutions obtained by a collection of meta-heuristic optimization methods for various experience cases are established, and the presented methods are compared according to the case study, limitation of parameters, optimization techniques, and consideration of the main goal. Previous studies are mostly focused on hydro scheduling that is based on a reservoir of hydropower plants. Future study aspects are also considered, which are presented as the key issue surrounding the LMSTHS problem.
\end{abstract}

Keywords: renewable energy; optimal generation scheduling; heuristic method; genetic algorithm; dynamic programming; hydropower generation 


\section{Introduction}

Many power generation units have been constructed in the past because of increasing power demand. The optimal generation scheduling (OGS) of accessible generation units is regarded as a significant subject in power systems, which is studied by academic authors in the field [1-3]. Long-, mid-, and short-term hydro scheduling (LMSTHS) optimization problems cause the OGS of cascaded hydropower plants to correspond to load demand in such a way that the entire operating expenses are minimized considering a diversity of constraints $[4,5]$. The LMSTHS problem should be optimized subject to a diversity of constraints of hydro units, including the balance of water and power, water release limits, limitations of water storage, and power generation. Furthermore, the unexpected variation of input parameters, losses of power transmission from generation units, and composite hydraulic connections describe the LMSTHS optimization problem as a non-linear and a non-convex problem [6-9]. Figure 1 shows a sample architecture for hydroelectric power generation.

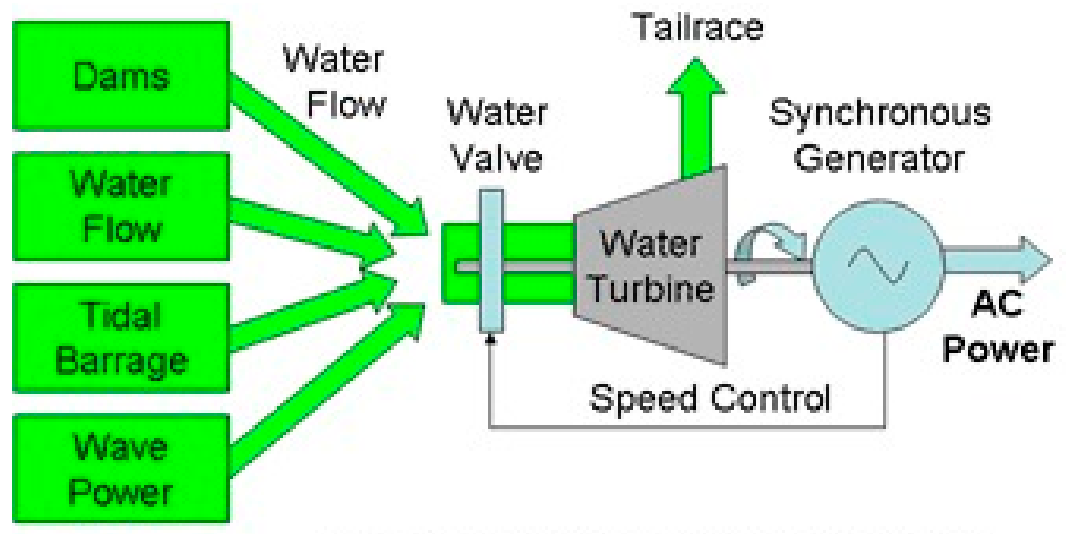

Figure 1. Hydroelectric power generation architecture [2].

The OGS of hydro units has been an exciting interest of academic authors, an extremely important study area, for several years. Numerous optimization methods have been suggested to solve this complicated problem. These include heuristic, deterministic, and hybrid optimization methods and classical mathematical optimization procedures, such as, firstly, mixed-integer linear programming (MILP) [10], the principle of the amount at risk is first executed and then a maximum amount theory-genetic algorithm (GA) [11] and non-linear programming models to get operating rules with various features [12] are used to obtain the optimal solution of the short-term hydro scheduling (STHS) problem. Secondly, for the mid-term hydro scheduling (MTHS) problem, real-time optimization [13], an evaluation method [14], dual dynamic programming (DDP), and stochastic DDP [15] are implemented. Thirdly, for the long-term hydro scheduling problem, dynamic programming (DP) and uniform DP [16], a cost-paid yearly optimization model according to discrete DP and the MILP [17], conventional particle swarm optimization (PSO), overall learning of the PSO and improved overall learning of the PSO [18], discrete differential dynamic programming and orthogonal discrete differential dynamic programming [19], a multi-objective complex evolution global optimization method with main factor investigation, and a congestion distance operator are also attempted.

A comparative assessment among the proposed methods-the conventional multi-objective complex evolution global optimization method, the multi-objective differential evolution method, the multi-objective GA, the multi-objective simulated annealing method, and the multi-objective PSO method-has been shown using the benchmark functions [20]. Recently, the gravity search algorithm according to the gravity rule and collective interactions is introduced. The algorithm efficacy is compared with that of the original GA to solve benchmark functions. Moreover, different mathematical methods, heuristic methods, and meta-heuristic methods have been recognized as methods based on experience, regarded as elastic, multipurpose, and effective in discovering the solution of non-convex and complicated non-linear problems [21]. 
The organization of this research review is as follows: Section 2 illustrates the detailed problem of the OGS of hydro units. The mathematical formulation highlighting the objective function and the constraints are presented in Section 3. In Section 4, a complete survey of the execution of common optimization methods for the OGS of hydro units is presented. Section 4 concludes the review.

\section{Review Methodology}

Many well-established reviews and survey articles on solving hydro generation scheduling are available in the literature, including [1,3,6]. The review of Yah et al. [1] clarifies the relevant research literature for small-scale hydropower technology and the challenges faced by the small renewable energy power industry in Malaysia. In the prior work of Binama [3], a state-of-the-art review on the two most challenging pump as turbine (PAT) aspects, namely PAT performance prediction and PAT flow stability aspects, are presented. Moreover, the work of Nazari [6] provides a review on the application of heuristic methods to obtain the optimal generation scheduling for hydrothermal systems, which compares the implemented procedures from different points of view, whereas the previous work assesses the state-of-the-art in hydropower operations considering profit-risk under uncertainty and considering future directions for additional research and applications. Figure 2 shows China's power capacity in 2014 and hydropower development from 1949 to 2014 (GW).

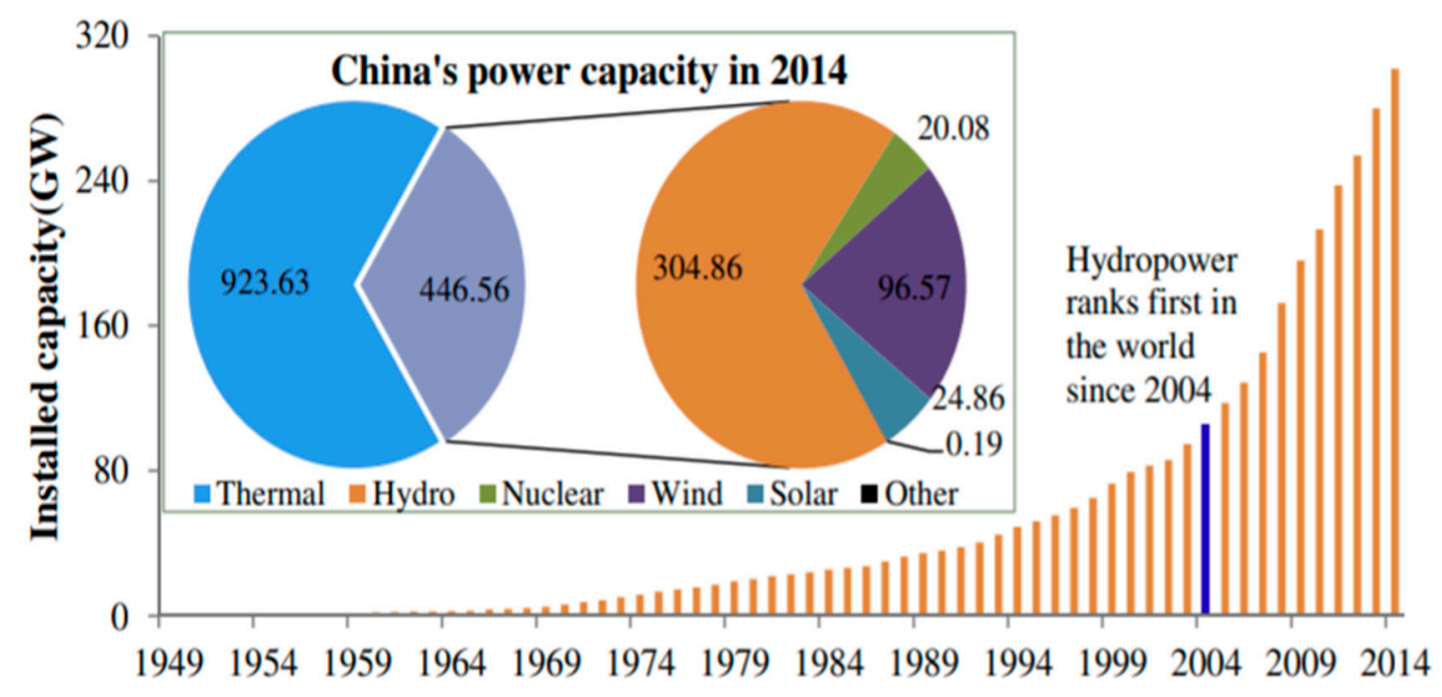

Figure 2. China's power capacity in 2014 and hydropower development from 1949 to 2014 (GW) [19].

Hydropower consists of a large scale of power generation plants, and the operation of such plants is very influential in accomplishing maximum generation at a minimum operating cost. This paper offers a complete survey of the implementation of various optimization methods to solve the power generation scheduling problem for hydro units. It also covers the ecological aspects and all the aspects of hydro generation scheduling.

The essential objective of this review article is to illustrate the previous studies of optimal hydro generation-including long-, mid-, and short-term hydro scheduling-comprehensively, with particular emphasis on the case study, limitation of parameters, optimization techniques, and consideration of the main goal. The LMSTHS problem is solved by the use of various methods, which include heuristic methods and mathematical programming procedures.

The work also aims to discover the future field for a research study on the scheduling aspects of all hydropower plants. Figure 3 shows the number of reviewed and discussed articles in this work based on the year of publication. A total of 96 articles are covered in this work that offers a complete survey of the implementation of various methods to get the OGS of hydro systems, which examines the methods from various perspectives. Optimal solutions are obtained by a collection of meta-heuristic optimization 
methods for various experience cases that are established, and the presented methods are compared according to the case study, limitation of parameters, optimization techniques, and consideration of the main goal. This review approach allows us to improve the scope and shape the direction of the OGS for hydro systems.

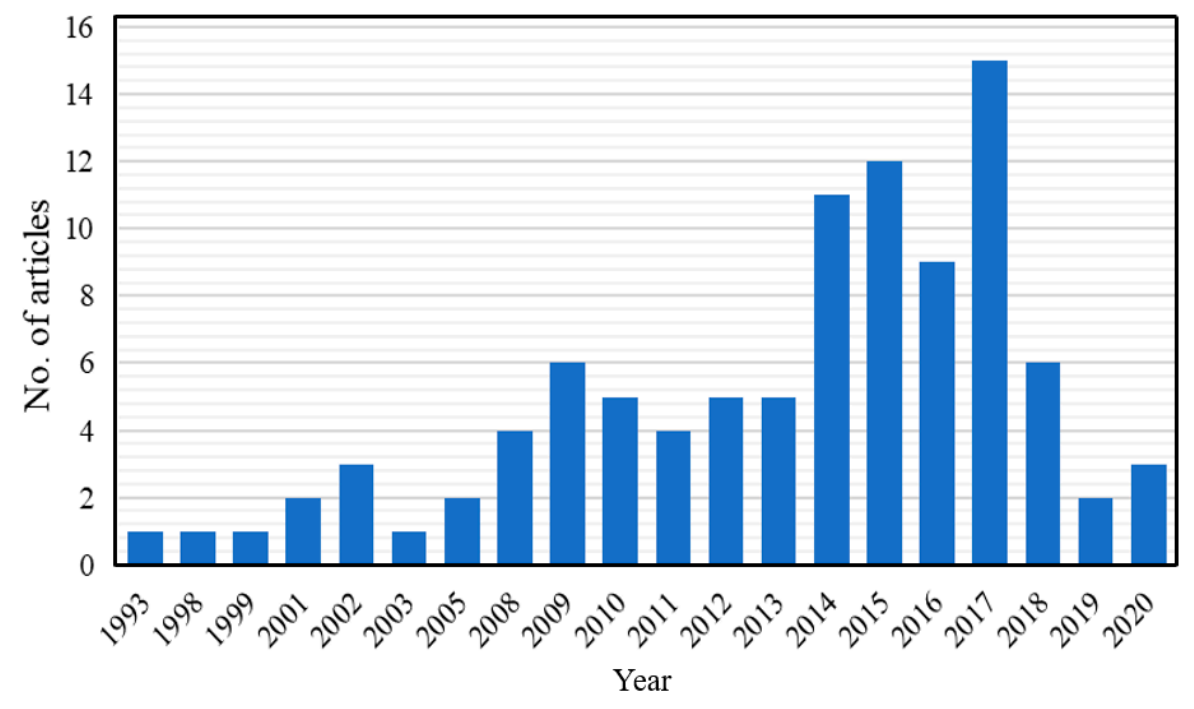

Figure 3. An overview of the reviewed articles.

\section{Mathematical Formulations}

\subsection{Objective Functions}

The objective function aims to maximize power production in the hydropower plant. In these optimization modules, the system seeks to use the maximum amount of water (plant turbine outflow) that meets the power target provided. Thus, the main objective of the long, mid, and short hydro generation scheduling is to assess the optimal water releases of hydro reservoirs and power generation of each unit so that the fitness function of forecasting power production is optimized, which is defined as follows:

$$
\max F_{\text {Fitnees }}=\sum_{i=1}^{I} \sum_{t=1}^{T} P p_{i} \Delta t
$$

where $i$ is the hydropower unit, and $i \in\{1, \ldots, I\}$ and $\mathrm{t}$ are related to time periods, $t \in\{1, \ldots, T\}$.

\subsection{Constraints}

1. Power Production Limits $\left(\mathrm{Pp}_{\mathrm{i}}\right)$ :

Each power production unit has production capacity boundaries:

$$
\begin{gathered}
u_{i} \times P p_{i}^{\min } \geq P p_{i} \geq u_{i} \times P p_{i}^{\max } \\
P p_{i}-\left(N h_{i} \times F r_{i} \times g_{i} \times \eta_{i}\right)=0 \\
\sum_{i}^{N} P p_{i}-P p_{t}=0
\end{gathered}
$$

$P p_{i}$ is considered to be a polynomial function of the water discharge rate and reservoir storage volume:

$$
P p_{i}=C h_{1 i} \times\left(R e_{i}\right)^{2}+C h_{2 i} \times\left(F r_{i}\right)^{2}+C h_{3 i} \times R e_{i} \times F r_{i}+C h_{4 i} \times R e_{i}+C h_{5 i} \times F r_{i}+C h_{6 i}
$$




$$
u_{i} \in\{0,1\}
$$

2. Net Head $\left(N h_{\mathrm{i}}\right)$ :

$$
\begin{gathered}
u_{i} \times N h_{i}^{\min } \leq N h_{i} \leq u_{i} \times N h_{i}^{\max } \\
\sum_{i=1}^{N} N h_{i}-N h_{t}=0
\end{gathered}
$$

where upstream is the water level in front of the hydropower plants and downstream is the water level in the back of the hydropower plants nearer to the river.

$$
\begin{gathered}
N h_{i}^{\text {max }}=\text { upstream }_{i}^{\text {max }}-\text { downstream }_{i}^{\text {max }} \\
N h_{i}^{\text {min }}=\text { upstream }_{i}^{\text {min }}-\text { downstream }_{i}^{\text {min }} \\
\text { upstream }_{i}^{\text {min }} \leq \text { upstream }^{\text {mopstream }}{ }_{i}^{\text {max }} \\
\text { downstream }_{i}^{\text {min }} \leq \text { downstream } \leq \text { downstream }_{i}^{\text {max }}
\end{gathered}
$$

3. Flow Rate $\left(F r_{\mathrm{i}}\right)$ :

$$
\begin{gathered}
u_{i} \times F r_{i}^{\text {min }} \leq F r_{i} \leq u_{i} \times F r_{i}^{\max } \\
\sum_{i=1}^{N} F r_{i}-F r_{t}=0
\end{gathered}
$$

4. Reservoir Water Storage Volume $\left(R e_{i}\right)$ Limit:

$$
u_{i} \times R e_{i}^{\min } \leq R e_{i} \leq u_{i} \times R e_{i}^{\max }
$$

5. Water Density $\left(\rho_{i}\right)$ and Temperature $\left(T e_{\mathrm{i}}\right)$ :

$$
\begin{gathered}
\rho_{i}^{\text {min }} \leq \rho_{i} \leq \rho_{i}^{\text {max }} \\
T e_{i}^{\text {min }} \leq T e_{i} \leq T e_{i}^{\text {max }}
\end{gathered}
$$

6. Efficiency $\left(\eta_{i}\right)$ :

$$
\eta_{i}^{\min } \leq \eta_{i} \leq \eta_{i}^{\max }
$$

\section{Research Review on the Hydropower Scheduling Problem}

The target of hydro scheduling is to maximize the gross utilization of the power generation of large cascaded hydropower plants during the entire specific intervals of time while constrained to different operational and environmental constraints. When the warranted energy production cannot not be enough, the main target is altered to maximizing the minimum energy production. The OGS of hydro units is implemented throughout the procedure for a specified horizon of time during the corresponding load demand [6,22].

Optimal hydro generation is difficult, and the major purpose is that decisions are time-dependent; the optimization problem contains state-variables, which include the water level in the reservoir and stochastic, weather-reliable variables, the most effective of which is water flow. Thus, the complete multi-dimensional optimization problem is divided into sub-problems. Regularly, long-, mid-, and shortterm sub-problems are detailed, and for each problem is made a solution by specified solution methods $[6,15,23]$, as presented in Figure 4. In this article, the hydro generation schedule is supposed to be covered by the proposed solutions for all time horizons. 


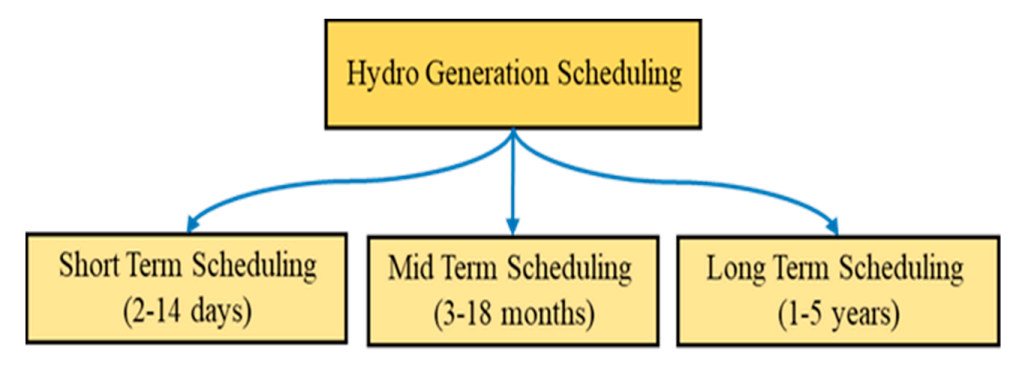

Figure 4. Hydro generation scheduling terms.

The previous research studies on hydro generation scheduling consider, typically, the hydropower plants based on the reservoir. In this research, a complete survey shows the various aspects of a hydropower plant such as the case study, limitation of parameters, optimization techniques, and consideration of the main goal, in the following subsections.

\subsection{Optimization of Short-Term Scheduling}

Gea et al. [24] considered the optimization of the water time delay, which is continuously changing and creates a difficult problem in dealing with the corresponding mathematical models. This study shows that the suggested model with a delay period for the water may enhance the operational ability and profitability of scheduling utilization. Catalão et al. [25] proposed a modern mixed-integer non-linear programming (MINP) technique, taking into account a non-linear function to release water and the net head. An improved approach is implemented because of the more reliable modeling and executed positively on cascaded hydro units with an ignored computational time condition. In Catalão et al. [26], they also consider not only head dependency but intermittent operating regions and water release limitations as well. Numerical results show the good performance of the suggested technique. Moreover, in Catalão et al. [27], they propose a new non-linear method to solve the problem of hydro scheduling with constraints satisfied, taking into account the head dependency. The results show that the suggested non-linear method is efficient.

Belsnes et al. [28] presented a model for operational stochastic hydropower scheduling. The proposed approach is based on stochastic successive linear programming. From this study, enhancements achieve the objective function value and reduce the risk of spills from reservoirs. Ge et al. [29] proposed a model that contains a non-linear function connected with the water delay time, which is based on a successive approximation method. The suggested method is verified with two-reservoir and ten-reservoir units. The numerical results prove that the suggested method provides realistic results.

Ma et al. [30] utilized the population initialization stage to improve the best individuals in the culture algorithm with differential evolution (DE). For a constant water release operation, there is a better base to choose an operation strategy in which the net head for hydropower generation is optimized and distributed economically for plant internal operation. Mo et al. [31] presented a hybrid algorithm utilizing the multi ant colony system and the DE method that are used to solve the sub-problems: unit commitment and economic load dispatch. The simulation results demonstrate that the suggested technique has the best convergence features and computational proficiency with less consumption for water discharge. Glotić et al. [32] considered the multi-population strategy to fulfil system requests with a reduced amount of water used in each generated unit. The initial and final statuses of the reservoirs were fulfilled as well.

Yuan et al. [33] suggested a new hybrid chaotic GA. Simulation results have verified that the solution method is possible and efficient for the applications. Chuanwen and Bompard [34] proposed a new self-adaptive chaotic PSO algorithm for the hydropower plant dispatch model according to the base of optimum utilization. The results show the proficiency and durability of the suggested approach in comparison with the original PSO algorithm. Li et al. [35] selected the support vector machine with 
GA since it displays several benefits in handling non-linear and high dimensional pattern recognition. By comparing its achievements, it is proven that the proposed model is a possible candidate for the optimum forecast of hydropower generation. Mu et al. [36] highlighted an effective method to enhance the operation solutions of hydropower plants in flood seasons. Three operation bases are validated with a numerical model by using the GA. Operation solutions with bases executed may be obtainable with better objective values and higher optimization proficiencies.

Séguin et al. [37] presented a new technique to resolve the unit commitment and loading problem for a determined hydropower system. The DP is employed to calculate the optimum output generated by a hydropower plant. Yuan and Zhou [38] discussed how to process the problems produced by doubts and achieve self-optimization for real-time hydropower operation. The results show that system dynamics simulation is a significant technique to model a composite cascaded hydropower plant with feedback and specific loops. Changing et al. [39] proposed multiple stages of discharge towards the outside of the upstream reservoir simultaneously with the discharge towards the inside of the downstream reservoir, which can be computed by the Muskingum model. The result of the operation of the proposed model produces additional advantages over realistic operation.

Jiekang et al. [40] presented a dynamic generation flow plan using the dynamically organizing net head of water in the reservoir and the consumption quantity of water. The results show that this new approach can improve the synthesis generation utilization of cascaded hydropower plants. Xin-Yu [41] composed the multi-objective optimal peak shaving model. It minimizes the maximum remaining loads per energy grid, which is an integral part of distributing the energy of a plant among some energy grids. A case study shows that the solution method is realistic, flexible and strong to get near-optimal results proficiently. Lu et al. [42] suggested a real binary bee colony optimization algorithm that is used to resolve parallel sub-problems of unit commitment and economic load dispatch. The simulation results prove that the suggested approach can obtain top-advantage solutions with shorter computing times and less water consumption. Marchand et al. [43] proposed a proficient model as a mixed-integer linear program, which shows a three-phase method based on a cost analysis that produces, rapidly, close optimal solutions to real-world cases. Ellen et al. [44] presented a model for hydropower bidding according to the OGS from a stochastic model. Furthermore, they presented a heuristic algorithm for decreasing the bid matrix into a size desired by a market operator. The results show how unchecked inflows may change the bids.

Naresh and Sherma [45] presented a proposed technique using two phases of a neural network. The results show that the suggested technique with a convenient choice of control parameters can generate and satisfy the optimal solution. $\mathrm{Xu}$ et al. [46] focused on the entire price of operating a cascaded reservoir system for the corresponding power demand that includes the price for the power source and the alternative price related to spillage. The results show that when immensely rainy hydrological circumstances are predictable, a compromise method is a superior plan. Castro et al. [47], highlighted the influence of operational choices on the market prices and the capability of regulating the tailwater level and the generation and pumping proficiencies as a function of the water inflow. As a result, the advantage of the operation of the hydro systems is assessed in a more realistic way, since market prices increase when pumping overrides generation and decrease if generation overrides pumping.

A summary of the research studies executed previously on the overall optimization methods used for the operation of short-term hydro scheduling is presented in Table 1. 
Table 1. Optimization of short-term hydro generation scheduling. Mixed-integer linear programming, MILP; mixed-integer non-linear programming, MINP; particle swarm optimization, PSO; optimal generation scheduling, OGS.

\begin{tabular}{|c|c|c|c|c|}
\hline Case Study & Limitation of Parameters & Optimization Techniques & Consideration of Main Goal & Ref. \\
\hline 44 units, China & $\begin{array}{l}\text { Balance, discharge, delay period, and outflow of water; } \\
\text { reservoir storage volume; generation. }\end{array}$ & MILP method & $\begin{array}{l}\text { Maximize the utility of energy production during the } \\
\text { outlining horizon. }\end{array}$ & [24] \\
\hline Portuguese & $\begin{array}{l}\text { Water conversion of the reservoir; head, storage, } \\
\text { discharge, and spillage of water; power generation. }\end{array}$ & MINP method & $\begin{array}{l}\text { Employed to model the on-off behaviour via integer } \\
\text { variables to avert inflows at prohibited regions. }\end{array}$ & [25] \\
\hline Two cases, Portuguese & $\begin{array}{c}\text { Parity and disparity constraints or unpretentious } \\
\text { variables of restrictions. }\end{array}$ & $\begin{array}{l}\text { A mixed-integer quadratic } \\
\text { programming method }\end{array}$ & $\begin{array}{l}\text { Model on-off behaviour to obtain realistic energy, } \\
\text { without affecting future operations. }\end{array}$ & [26] \\
\hline Portuguese & $\begin{array}{c}\text { Balance, head, storage, discharge, and spillage of water; } \\
\text { power generation. }\end{array}$ & A non-linear approach & Considering head-dependency. & [27] \\
\hline Norwegian industry & The uncertainty of water inflow and upcoming costs. & Stochastic successive linear programming & $\begin{array}{l}\text { Employed a first-order approximation to the } \\
\text { optimization of water head. }\end{array}$ & [28] \\
\hline 34 hydro units, China & $\begin{array}{l}\text { Level and hydraulic coupling of reservoirs; release and } \\
\text { the flow of water; power production. }\end{array}$ & Successive approximation approach & $\begin{array}{l}\text { The constant difference for a delay period of water to } \\
\text { define operations realistically exhaustive. }\end{array}$ & [29] \\
\hline Gezhouba and Gorges, China & $\begin{array}{l}\text { Water discharge; hydraulic head; online/offline time; } \\
\text { reservoir water level. }\end{array}$ & $\begin{array}{l}\text { Culture algorithm with } \\
\text { differential evolution }\end{array}$ & $\begin{array}{l}\text { Maximize the electrical power generation through an } \\
\text { entire dispatch interval. }\end{array}$ & [30] \\
\hline $\begin{array}{l}\text { Three Gorges-Gezhouba, } \\
\text { China }\end{array}$ & $\begin{array}{l}\text { Balance, discharge, and head of water; power balance; } \\
\text { uptime/downtime; turbine-generator capacity; reservoir } \\
\text { storage volume. }\end{array}$ & $\begin{array}{l}\text { Hybrid multi ant colony system with } \\
\text { adaptive deferential evaluation }\end{array}$ & $\begin{array}{l}\text { Locate which unit ought to be on and the standards at } \\
\text { which to produce energy in per unit to match the } \\
\text { specific energy request with full water consumption. }\end{array}$ & [31] \\
\hline Slovenia & $\begin{array}{l}\text { Min and max for reservoir volume; permissible } \\
\text { variation in the reservoir; production energy; discharge. }\end{array}$ & $\begin{array}{l}\text { Parallel Self-Adaptive } \\
\text { Differential Evolution }\end{array}$ & $\begin{array}{l}\text { Optimal production distribution via minimizing the } \\
\text { utilized water volume in each generated unit. }\end{array}$ & [32] \\
\hline Benchmark of two examples & $\begin{array}{l}\text { Hydropower generation; dynamic balance and } \\
\text { discharge of water; reservoir storage volume. }\end{array}$ & A hybrid chaotic genetic algorithm & $\begin{array}{l}\text { Discovery of the optimum hydro generation units in } \\
\text { each hour to employ the restricted resource of water. }\end{array}$ & [33] \\
\hline Hubei, China & $\begin{array}{l}\text { Dynamic balance and discharge of water; reservoir } \\
\text { storage volume; hydropower generation. }\end{array}$ & A self-adaptive chaotic with PSO & $\begin{array}{l}\text { The optimal dispatching is by maximum generation } \\
\text { considering the security conditions and reliability. }\end{array}$ & [34] \\
\hline Yunnan, China & $\begin{array}{l}\text { Installed capacity utilization hour; } \\
\text { hydropower generation. }\end{array}$ & $\begin{array}{l}\text { Genetic algorithm with support } \\
\text { vector machine }\end{array}$ & Power generation energy prediction. & [35] \\
\hline Three-gorge dam, China & $\begin{array}{c}\text { Maximum volume of water discharge; initial level in the } \\
\text { water reservoir. }\end{array}$ & Developed a genetic algorithm. & $\begin{array}{l}\text { Establish the operation principle values for } \\
\text { optimal decisions. }\end{array}$ & [36] \\
\hline Saguenay-Lac-St-Jean, Canada & $\begin{array}{l}\text { Unit commitment and loading problem; hydro } \\
\text { generation; turbine-generator efficiency; gravity } \\
\text { acceleration; turbine net head and water discharge. }\end{array}$ & Dynamic programming & $\begin{array}{l}\text { Dispatches energy production among units and } \\
\text { explores to optimize gross generation and select the } \\
\text { unit commitment and make discipline unit start-ups. }\end{array}$ & [37] \\
\hline
\end{tabular}


Table 1. Cont.

\begin{tabular}{|c|c|c|c|c|}
\hline Case Study & Limitation of Parameters & Optimization Techniques & Consideration of Main Goal & Ref \\
\hline Qing River, China & $\begin{array}{l}\text { Uncertainties of inflow containing its local and } \\
\text { upstream outflow; temporary power instructions. }\end{array}$ & Self-Optimization System Dynamics & Operation including real-time. & [38] \\
\hline Sichuan, China & $\begin{array}{l}\text { Balance, storage capacity, and outflow of water; } \\
\text { expected output. }\end{array}$ & $\begin{array}{l}\text { Multi-Stage Dynamic } \\
\text { Programming method }\end{array}$ & $\begin{array}{l}\text { Uses maximum power generation criterion to } \\
\text { establish reservoirs optimal operation. }\end{array}$ & [39] \\
\hline 8 stations, China & $\begin{array}{l}\text { Volume, head of water; reservoir storage volume; power } \\
\text { output; dealing within/non-equality. }\end{array}$ & Electromagnetism-like algorithm. & $\begin{array}{l}\text { Realize the optimal power output and to define its } \\
\text { relationship with the existing level of water. }\end{array}$ & [40] \\
\hline State Grid of China & $\begin{array}{l}\text { Energy loads per grid; primary storage of reservoir; } \\
\text { domestic inflow of reservoir; energy production; storage } \\
\text { of reservoir; turbine inflow and spill. }\end{array}$ & Local search algorithm & $\begin{array}{l}\text { Acquire nearer to the OGS for a group of hydropower } \\
\text { units on some rivers and transmit produced energy to } \\
\text { some energy grids. }\end{array}$ & [41] \\
\hline $\begin{array}{l}\text { Xiluodu and Xiangjiaba, } \\
\text { China }\end{array}$ & $\begin{array}{l}\text { Hydraulic connection; reservoir storage; water } \\
\text { discharge and balance; forbidden operating areas; limits } \\
\text { of hydropower system; uptime/downtime. }\end{array}$ & $\begin{array}{l}\text { Developed binary-real bee colony } \\
\text { optimization algorithm }\end{array}$ & $\begin{array}{l}\text { Minimize the gross water exhaustion, taking into } \\
\text { account enough demands of load and } \\
\text { different restrictions. }\end{array}$ & [42] \\
\hline Québec, Canada & $\begin{array}{l}\text { Water reservoirs; what comes in and out of the rivers } \\
\text { and the transit capacity in the river divisions; possible } \\
\text { delays; head and flow of water; production. }\end{array}$ & Fast Near-Optimal Heuristic & $\begin{array}{l}\text { Maximize the stored value of water in the reservoirs at } \\
\text { the scheduling end, maximize the final water quantity } \\
\text { and control the variations in turbine discharge. }\end{array}$ & [43] \\
\hline Norwegian watercourse & $\begin{array}{l}\text { The inflow uncertainty function when setting the } \\
\text { maximum values of bids. }\end{array}$ & Heuristic algorithm. & $\begin{array}{l}\text { Demonstration of how prototypes can be expanded to } \\
\text { grant a maximized curve of bids. }\end{array}$ & [44] \\
\hline Block diagram & $\begin{array}{l}\text { Load balance; spillage modeling; water flow and } \\
\text { reservoir storage volume; turbine net head. }\end{array}$ & Two-phase neural network & $\begin{array}{l}\text { Minimize the production costs for non-hydraulic } \\
\text { power through the period of schedule. }\end{array}$ & [45] \\
\hline Qingjiang, China & $\begin{array}{l}\text { Load balance; balance and storage of daily water; daily } \\
\text { average and limits for power output. }\end{array}$ & Multi-objective optimization model & $\begin{array}{l}\text { Maximizing the stored power in the hydropower units } \\
\text { and minimizing the gross discharge of water. }\end{array}$ & [46] \\
\hline Douro River, Portuguese & Flow and head of water. & The Linprog Function & $\begin{array}{c}\text { To set hydropower plants as price producers to get a } \\
\text { more practical model. }\end{array}$ & [47] \\
\hline
\end{tabular}


In daily-term scheduling optimization, Mengfei et al. [48] proposed a hybrid approach that merges discrete differential DP with the progressive optimality algorithm. To correspond to the realistic operational requirements of the power grid, a utilization maximization model is developed, in which the peak shaving requirements are used as constraints. With this unit-commitment plan, the calculation speed may be faster, and the estimated optimal solutions may be obtained in a sensible period. Yuan et al. [49] suggested a chaos concept to get self-adaptive parameter settings in the DE method. The suggested approach is verified with four interconnected cascaded hydropower units, and the experience results are validated with those obtained by the conjugate gradient and two-phase neural network technique to prove the superiority of the proposed solution. Moreover, they proposed an enhanced PSO algorithm using chaotic sequences [50]. The simulation results show that both of the suggested approaches can get top quality solutions. Moreno and Kaviski [51] highlighted an adjusted PSO algorithm. It is executed to achieve the maximum water benefit and with all constraints associated with synchronous water discharge. Computational evidence and comparisons with other heuristics approaches such as simulated annealing proved the efficiency of the solution method. A summary of the research studies executed previously on overall optimization methods used for the operation of daily-term hydro scheduling is presented in Table 2.

Table 2. Optimization of daily-term hydro generation scheduling.

\begin{tabular}{|c|c|c|c|c|}
\hline Case Study & Limitation of Parameters & Optimization Techniques & Consideration of Main Goal & Ref. \\
\hline Zagunao River, China & $\begin{array}{l}\text { Peak shaving; equations of water; } \\
\text { spinning-reserve; } \\
\text { uptime/downtime; limits of the } \\
\text { generator and prohibited } \\
\text { operating zones. }\end{array}$ & $\begin{array}{c}\text { Discrete differential } \\
\text { dynamic programming }\end{array}$ & $\begin{array}{l}\text { Acquire additional benefit for } \\
\text { power generation with a confirmed } \\
\text { water volume based on the real } \\
\text { requests of the energy grid. }\end{array}$ & [48] \\
\hline $\begin{array}{l}\text { Numerical simulation } \\
\text { example }\end{array}$ & $\begin{array}{l}\text { Hydropower production; turbine } \\
\text { inflow; the net head of the } \\
\text { reservoir; delay period for the } \\
\text { water transfer. }\end{array}$ & $\begin{array}{l}\text { An enhanced differential } \\
\text { evolution algorithm; } \\
\text { chaos theory }\end{array}$ & $\begin{array}{l}\text { Minimize the variation summation } \\
\text { between the gross generation of } \\
\text { hydropower system and the load } \\
\text { request per hour during the period } \\
\text { of dispatching. }\end{array}$ & [49] \\
\hline Numerical simulation & $\begin{array}{c}\text { Load balance; limits of generation; } \\
\text { water discharge; reservoir storage } \\
\text { volumes; transport delay time. }\end{array}$ & Enhanced PSO algorithm & $\begin{array}{l}\text { Minimize the gross expenses while } \\
\text { utilizing the accessibility of the } \\
\text { hydro exporter as far as possible. }\end{array}$ & {$[50]$} \\
\hline $\begin{array}{l}\text { Brazilian Power } \\
\text { System }\end{array}$ & $\begin{array}{l}\text { Generation and outflow of the } \\
\text { hydro plant; reservoir storage } \\
\text { volumes; water dynamic balance. }\end{array}$ & Adjusted PSO algorithm & $\begin{array}{l}\text { Maximize the gross hydropower } \\
\text { production to meet different } \\
\text { material and } \\
\text { operational constraints. }\end{array}$ & [51] \\
\hline
\end{tabular}

\subsection{Optimization of Mid-Term Scheduling}

Shrestha et al. [52] addressed the optimal organization of hydropower properties based on optimizing the expected profits of a provider, and the decision variables are generation and future contracts per interval of time. Baslis et al. [53] presented a stochastic self-scheduling model for a hydro cost provider. The provider intends to optimize revenues in the daily markets. The results indicate the possibility of getting a unique commercial solver. Catalão et al. [54] proposed a new contribution to market volatility, which is presented in a model using cost strategies and risk management via conditional value-at-risk concept to prevent revenue volatility. Furthermore, plant scheduling and pool contribution by hydropower providers are concurrently considered to provide a solution for practically cascaded hydro units.

Flatabø et al. [55] established a plan to operate the generation system for a period of time. The arrangement of the turbine and spill capacities of water is such that it minimizes the predictable operational expenses. Huber et al. [56] presented a modeling method, in which the real accessible electricity market provides the source of data for the model. A benefit of this modeling method includes the normal consideration of power future that provides hourly price curves. Besides, the model can unify the optimizations. Moreover, they proposed a method to contain the capability of contribution to secondary control. The output is an approximation of water quantities for use in the optimization and optimal contribution of secondary control [57]. They also proposed an approach based on Lagrangian 
relaxation, which is employed to discover realistic quantities of water [58]. Arild et al. [59] described an approach for optimal scheduling, a revenue optimizing, price-taking approach with neutral risk to the provider for the exported energy and the ability to isolate and serially clear markets. Martin et al. [60] assessed the quantity for producing initial reserves and how significant correct modeling is for selling ability. It was discovered that the predictable revenue from selling ability decreased by $40 \%$ when the simulator results are compared with the planning model.

Aquino et al. considered a recurrent [61] and hybrid intelligent [62] two-phase optimization neural network to resolve the economic dispatch of power that minimizes the total cost of production with the corresponding load demand. The results show that the enhanced model delivers optimal scheduling that gives orientation to the minimal cost of operation. Lotfi and Ghaderi [63] proposed a new possibilistic price according to the MILP method. The result shows the capability and suitability of the suggested method, and it may be simply executed for a regulated environment. A summary of the research studies executed previously on overall optimization methods used for the operation of mid-term hydro scheduling is presented in Table 3.

Table 3. Optimization of mid-term hydro generation scheduling.

\begin{tabular}{|c|c|c|c|c|}
\hline Case Study & Limitation of Parameters & Optimization Techniques & Consideration of Main Goal & Ref. \\
\hline $\begin{array}{l}\text { Nord Pool, } \\
\text { Norway }\end{array}$ & $\begin{array}{l}\text { Reservoir balance of water; upper and } \\
\text { lower limit of generation, contract, } \\
\text { and reservoir; spillage. }\end{array}$ & $\begin{array}{l}\text { Stochastic linear and } \\
\text { non-linear programming. }\end{array}$ & $\begin{array}{l}\text { To determine the OGS and the } \\
\text { extent of binary contracts. }\end{array}$ & [52] \\
\hline $\begin{array}{l}\text { Greek Power } \\
\text { System }\end{array}$ & $\begin{array}{l}\text { Uncertainty of turbine discharges, } \\
\text { load request, and rivals' quotes. }\end{array}$ & $\begin{array}{l}\text { Stochastic mixed-integer } \\
\text { linear programming. }\end{array}$ & $\begin{array}{l}\text { To optimize financial revenue and } \\
\text { making use of manipulating } \\
\text { market costs. }\end{array}$ & [53] \\
\hline Portugal & $\begin{array}{l}\text { Balance, head, storage, discharge, } \\
\text { discharge ramping, and spillage of water; } \\
\text { power generation; commitment. }\end{array}$ & $\begin{array}{l}\text { Mixed-integer non-linear } \\
\text { programming. }\end{array}$ & $\begin{array}{l}\text { Realize the best quotes by } \\
\text { determining the plans of bids in } \\
\text { the daily markets. }\end{array}$ & [54] \\
\hline Norway & $\begin{array}{l}\text { Contents and spillage of the reservoir; } \\
\text { water flow pumping capability; } \\
\text { demand and supply of power. }\end{array}$ & Stochastic DDP. & $\begin{array}{l}\text { Establish system operation and } \\
\text { contribute to minimizing the } \\
\text { expected future operational costs. }\end{array}$ & [55] \\
\hline $\begin{array}{l}\text { Swiss hydro } \\
\text { system }\end{array}$ & $\begin{array}{l}\text { Taking part in the over-the-counter, } \\
\text { power futures, options, day-ahead, } \\
\text { and spot markets. }\end{array}$ & $\begin{array}{l}\text { Stochastic dynamic } \\
\text { programming. }\end{array}$ & $\begin{array}{l}\text { Optimization depending on } \\
\text { hourly price forward curve. }\end{array}$ & [56] \\
\hline $\begin{array}{l}\text { Swiss hydro } \\
\text { system }\end{array}$ & $\begin{array}{c}\text { Upper and lower basin level and water } \\
\text { inflows; the water levels in the basins } \\
\text { have negligible influence. }\end{array}$ & $\begin{array}{l}\text { Integrating ancillary } \\
\text { services. }\end{array}$ & $\begin{array}{l}\text { An optimal offering of secondary } \\
\text { control of cost-taker hydropower } \\
\text { generators with pumped storage. }\end{array}$ & [57] \\
\hline $\begin{array}{l}\text { Swiss hydro } \\
\text { system }\end{array}$ & $\begin{array}{l}\text { Processes of avoiding risk, saving of } \\
\text { stores for spinning, and hydropower } \\
\text { generation flexibility. }\end{array}$ & Stochastic DDP. & $\begin{array}{c}\text { Discovery of realistic quantities of } \\
\text { water that was supported by } \\
\text { national legal cuts. }\end{array}$ & [58] \\
\hline $\begin{array}{l}\text { Norwegian } \\
\text { watercourse }\end{array}$ & $\begin{array}{l}\text { Inflow handling to reservoirs, } \\
\text { their volumes, hydro energy costs. }\end{array}$ & Stochastic DDP. & $\begin{array}{l}\text { Determine equivalent } \\
\text { involvement in the daily ability } \\
\text { markets and its reserve. }\end{array}$ & [59] \\
\hline $\begin{array}{l}\text { Lysebotn, } \\
\text { Norway }\end{array}$ & $\begin{array}{l}\text { Balance of energy and reservoir; } \\
\text { springing reserve, startup cost; hydro } \\
\text { coupling; power discharge function. }\end{array}$ & Stochastic DDP. & $\begin{array}{l}\text { Fulfil the hydropower units } \\
\text { operators' demands to get steady } \\
\text { operation for the grid. }\end{array}$ & [60] \\
\hline $\begin{array}{l}\text { Parnaiba river, } \\
\text { Brazil }\end{array}$ & $\begin{array}{l}\text { Storage, discharge from of bounds on the } \\
\text { reservoir; initial volume and target } \\
\text { volume; hydraulic generation. }\end{array}$ & $\begin{array}{l}\text { Two-phase optimization } \\
\text { neural network. }\end{array}$ & $\begin{array}{l}\text { Minimize the overall production } \\
\text { cost while satisfying the } \\
\text { load demand. }\end{array}$ & {$[61,62]$} \\
\hline Guilan, Iran & $\begin{array}{c}\text { Accessibility of energy production units; } \\
\text { obtainable water in hydropower } \\
\text { units reservoir. }\end{array}$ & $\begin{array}{c}\text { Possibilistic } \\
\text { programming approach. }\end{array}$ & $\begin{array}{l}\text { Set the production, selling and } \\
\text { purchasing units of generation } \\
\text { company for the following season. }\end{array}$ & [63] \\
\hline
\end{tabular}

\subsection{Optimization of Long-Term Scheduling}

Zhao et al. [64] proposed a constrained Markov decision method for managing the water discharge to satisfy water supply conditions and the system requirements for electric power and to minimize the entire expenses of energy production. Numerical results prove the activity and the proficiency of the configuration and the solution method. Scarcelli et al. [65] presented the Markovian stochastic DP by modeling monthly discharges based on possibility distribution functions. The results demonstrate that the production of regular and proposed programs is very similar, corresponding to an average of 
spillage and power generation but with cheaper costs. Scarcellia et al. [66] proposed monthly discharges based on possibility distribution functions. The results show that the solution method produces spillage that decreases and increases in electrical energy production, which reduces operational costs by up to $2.1 \%$.

Birger Mo et al. [67] presented a method of operation scheduling and economic hedging by future contracts that are combined in a unique model. The method may be valuable for hydropower firms that cover cost risks as well as the discharge volatility. In [68], they described the structure of the cost model and its identification that is employed in the stochastic optimization of hydro operation and adjustable contracts. The result shows how the cost model is employed to combine hydro operation and economic hedging. Hongling et al. [69] assessed state-of-the-art techniques like Tree Captures (TC), the Clustering Method (CM), the Heuristic Method (HM), the Stochastic of the DP, and Monte-Carlo Simulation (MCS), in which considerations focus on the revenue produced by volatility in instant costs and reservoir discharge. Moreover, generation sources can also be employed to control risk to some extent. Larsen et al. [70] proposed a linear time series model based on stochastic discharge that considers flood season and lag-one autocorrelation as well as the strategy of decrease based on reducing the size of a conventional strategy set while retaining the wasted stochastic information included. The results show that the selection of the strategy of decrease technique affects the solution to the planning problem of hydropower operation considerably. Hjelmeland et al. [71] proposed a stochastic DDP scheduling model according to mixed integer programming (MIP). The predictable revenue from the selling ability of the linear stochastic DDP model was $29.2 \%$ greater than that from the simulator model. The total revenue wasted reduces by $0.93 \%$, quantifying the overestimation of revenue in the proposed model.

Baohong et al. [72] introduced three optimization approaches including the progressive optimization algorithm, the PSO, and the GA. The minimum rate of water inflow consumption is selected as the objective function. After comparing the effects of the three approaches, the progressive optimization algorithm is discovered to be more suitable for the Zhelin reservoir. Mengfei et al. [73] considered the prediction error that occurs in monthly forecasting of the flow of watercourses and suggested an approach named the predicting dispatching chart for Xiluodu and Xiangjiaba cascaded hydro plants. The chart has been verified for realistic operations and realizes enough production.

Cheng et al. [74] proposed a new chaotic GA. The results show that the average yearly power is the largest, and its convergent speed is not only quicker than the DP but exceeds that of the GA as well. Therefore, the solution method is possible and efficient for the optimal operations of composite reservoir units. Yao-Yao et al. [75] presented a new chaotic PSO algorithm and makes a comparison between the proficiency of one- and three-dimensional chaotic charts within a regular range. Statistical results and validations prove the influence and speed of various algorithms for a realistic hydro-system. Hammid and Sulaiman [76] focused on the enhancement of the optimization model by using the PSO and Firefly Algorithm (FA) approaches to obtain a steady utilization of power generation at its optimum level. The results show the robustness of the FA, its proficiency and its excellence. They have made a new strategy to improve PSO and FA via a series division method as well. The results show that the Series Division Firefly Algorithm is robust and has good efficiency and superiority [77]. Lia et al. [78] proposed a multi-core parallel PSO algorithm. The results show the enhancement of the efficiency, the dependability of the optimal production, and its low execution price. The proposed method has a high possibility for future optimal operation.

Zhang et al. [79] proposed a multi-objective adaptive DE with a chaotic neural network. The proficiency of the proposed algorithm is obtained to compare with multi-objective optimization algorithm and demonstrates that it can be an assuring choice and deliver optimal trade-offs for multi-objective reservoir operation. Wang et al. [80] proposed multi-population ant colony optimization for a continuous domain. The effectiveness and steady state of the proposed algorithm are validated by its further acceptable outcomes. The system can get more power generation gain than other choices during a wet, normal and dry year. 
Liao et al. [81] formulated an economic dispatch of hydropower systems and analyzed the accomplishments of three various principles of the control parameter adjustment standard. Then, the accomplishment of the suggested algorithm is compared with that of different algorithms like the PSO. Liao et al. [82] presented a modern multi-objective evolutionary algorithm called the multi-objective artificial bee colony algorithm. Statistical results prove the performance and proficiency of the suggested algorithms, which have better convergence speed and satisfy the distribution of the Pareto front.

Zambelli et al. [83] proposed a yearly discharge predicting model in an open-loop feedback control operational strategy. In Zambelli et al. [84], they proposed a predictive control according to deterministic non-linear optimization and yearly discharge predicting models. The production of the suggested method is compared with that of the stochastic DP method. The results illustrate that both solution methods indicate an operational production nearer to that of an excellent solution, producing higher average hydropower generation and lower spillages of the reservoir. Moreover, in Zambelli et al. [85], they proposed a novel deterministic method based on adaptive model predictive control. In comparison, the suggested method is discovered to deliver a better product because of the increased effective utilization of water sources, causing a safer and cost-effective operation.

Mantawy et al. [86,87] proposed a Tabu search algorithm and introduced novel concepts for generating possible solutions with a flexible stage vector orientation. The statistical results illustrate an enhancement in the introduced solution compared with earlier solutions.

Nabona [88] employed deterministic discharges for the case of the discharge that is delivered as possibility density functions via multicommodity network discharges. It has been illustrated that problems including numerous reservoir units with incomplete reliance on discharges can be passably modeled as well. Fosso et al. [89] created a model based on maximizing generation by taking into account the spot market cost. The result shows how to implement the management computations for water value. Fleten et al. [90] presented a multi-stage stochastic MIP model that has a current tax time decision and a harsher decision in the future. It treats cost as a stochastic parameter and considers deterministic water discharge as it is designed for treatment in the wintertime period. Grønvik et al. [91] proposed linear decision rules that optimize the market price from the energy production sale in a good performance market. The uncertainty concept is included in market costs and reservoir discharges. The results show that the suggested estimation is efficient at reducing the complexity of computations. Guisández et al. [92] considered water discharge as another case variable to determine the problem case description. The results of the water discharge as a state variable does not illustrate an important influence in the expected yearly profits, but assured variations are recognized for specified time intervals of the year that might prove its deliberation in fewer period prospects. Xiaolin et al. [93] aimed to explore the possibility of power generation and load requests. The results show that the cost-effectiveness of the system is developed when power generation and load requests are combined in the scheduling.

Sharma et al. [94] presented the optimum exploitation of accessible hydro sources in all parts of the country with minimum ecological influences. It not only satisfies the country's power demand but also provides power to the north grid to support the general progress of the country. Zhao et al. [95] determined the optimum ability endurance of storage between tight, minimal cost increment and reduced minimal return. The results support the analytical decisions and show that the minimal return from the ability endurance of storage is larger than the minimal cost. Molina and Soares [96] presented the evaluation efficiency of a simulation model that proves a scientific application using two fundamental comparisons of the model: a hydropower generation function and the balanced equation of water. The results show that the simulation model may be exaggerating, by more than $3 \%$, the hydropower production of the recognized plants. A summary of the research review executed on the overall optimization methods used for the operation of long-term hydro scheduling is presented in Table 4. 
Table 4. Optimization of long-term hydro generation scheduling. Tree captures, TC; clustering method, CM; heuristic method, HM; dynamic programming, DP; dual dynamic programming, DDP; genetic algorithm, GA; Monte-Carlo simulation, MCS.

\begin{tabular}{|c|c|c|c|c|}
\hline Case Study & Limitation of Parameters & Optimization Techniques & Consideration of Main Goal & Ref. \\
\hline Yellow River, China & $\begin{array}{l}\text { Annual consumption, release, and storage of water; } \\
\text { cost structure. }\end{array}$ & Constrained Markov decision process & $\begin{array}{l}\text { Determining the water release and to minimize the } \\
\text { total energy production cost. }\end{array}$ & [64] \\
\hline Hydro plants, Brazil & $\begin{array}{l}\text { Hydro generation; head, discharge, and density of } \\
\text { water; gravity acceleration; average efficiency. }\end{array}$ & Markovian stochastic DP & $\begin{array}{l}\text { Minimizing the predictable quantities of the operating } \\
\text { expense by considering discharges. }\end{array}$ & [65] \\
\hline Sobradinho, Brazil & $\begin{array}{l}\text { Time; cost; load demand; efficiency; discharge and head } \\
\text { from turbine; spillage; forebay/tailrace function. }\end{array}$ & Markovian stochastic DP & $\begin{array}{l}\text { Monthly inflow for single-reservoir } \\
\text { hydropower systems. }\end{array}$ & [66] \\
\hline Røldal/Suldal Scandinavia & $\begin{array}{l}\text { Balance of water and reservoir; contract balance of } \\
\text { future period, spot market, and accumulation of profit. }\end{array}$ & Stochastic DDP & $\begin{array}{l}\text { Obtain a firm's risk management to maximize an } \\
\text { outlined interval separable advantage task. }\end{array}$ & [67] \\
\hline Norsk Hydro, Norway & $\begin{array}{l}\text { Modified transition probabilities; cost node numbers; } \\
\text { the medium cost in a period time of stage for cost node. }\end{array}$ & Stochastic DDP approach & $\begin{array}{l}\text { To assess the transmission prospects for cost from the } \\
\text { previous week and beyond. }\end{array}$ & [68] \\
\hline Yalong River, China & $\begin{array}{l}\mathrm{Min} / \mathrm{max} \text { level of release and storage for the reservoir at } \\
\text { the overall/end of time; max/min of generation. }\end{array}$ & TC; CM; HM; MCS; stochastic DP & $\begin{array}{l}\text { Generate energy and sell with the best revenue with } \\
\text { minimum market risks. }\end{array}$ & [69] \\
\hline Tokke Sys., Norway & $\begin{array}{l}\text { Equations of water balance; reservoir capacity } \\
\text { limitations; inflows of water for each reservoir at plants. }\end{array}$ & Stochastic DDP & $\begin{array}{l}\text { To solve an inherently stochastic problem because of } \\
\text { the uncertainty upcoming discharge of the reservoir. }\end{array}$ & [70] \\
\hline South-west, Norway & $\begin{array}{l}\text { Reservoir balance; energy balance including inflow and } \\
\text { generation; start-up expenses; the amount of capacity } \\
\text { available for sale; primary frequency reserve. }\end{array}$ & Stochastic DDP & $\begin{array}{l}\text { To produce a performance metric of the revenue } \\
\text { assignment to reach convergence. }\end{array}$ & [71] \\
\hline Jiangxi, China & $\begin{array}{l}\text { Balance, level, and the outflow of water; power output; } \\
\text { non-negative constraints. }\end{array}$ & Progressive optimization algorithm & $\begin{array}{l}\text { Optimal reservoir scheduling to completely utilize } \\
\text { water exported and make it economical. }\end{array}$ & [72] \\
\hline Xiangjiaba, China & $\begin{array}{l}\text { The capacity of reservoir storage; head and inflow of } \\
\text { water; power generation; hydro plant network. }\end{array}$ & Improved parallel progressive optimality & $\begin{array}{l}\text { Maximize the gross energy production of entire hydro } \\
\text { plants throughout the dispatching time. }\end{array}$ & [73] \\
\hline Nanpan River, China & $\begin{array}{l}\text { Storage volume and discharge of reservoir; power } \\
\text { generation; water balance. }\end{array}$ & Chaos in the GA & $\begin{array}{l}\text { Maximize generation output based on the reservoir } \\
\text { discharges chronologically. }\end{array}$ & [74] \\
\hline Three Gorges, China & $\begin{array}{l}\text { Balance, discharge, and the level volume of water; } \\
\text { capacities of reservoir storage; the level of river water; } \\
\text { hydro generation. }\end{array}$ & Chaotic maps in the PSO algorithm & $\begin{array}{l}\text { Maximize the gross revenue of the energy production } \\
\text { and distribution during a long period. }\end{array}$ & [75] \\
\hline Himreen lake dam, Iraq & $\begin{array}{l}\text { Net head of turbine; flow rate and density of water; } \\
\text { hydropower system efficiency. }\end{array}$ & Firefly algorithm and PSO & $\begin{array}{l}\text { To estimate optimal discharge of water of hydro } \\
\text { reservoirs and energy production per unit. }\end{array}$ & [76] \\
\hline Himreen lake dam, Iraq & $\begin{array}{l}\text { Net head of turbine; flow rate and density of water; } \\
\text { hydropower system efficiency. }\end{array}$ & Series division method with FA and PSO & $\begin{array}{l}\text { To estimate optimal discharge of water of hydro } \\
\text { reservoirs and energy production per unit. }\end{array}$ & [77] \\
\hline Three Gorges, China & $\begin{array}{l}\text { Balance, level, and discharge of water limits; power } \\
\text { generation limits. }\end{array}$ & Multi-Core Parallelization of PSO & $\begin{array}{l}\text { To discover the optimum plan for maximum power } \\
\text { generation through the operation interval. }\end{array}$ & [78] \\
\hline Three Gorges, China & $\begin{array}{l}\text { Level, head, discharge, and balance of water; reservoir } \\
\text { storage conversion; output generation. }\end{array}$ & Multi-objective adaptive differential evolution & $\begin{array}{l}\text { Minimum environmental shortage and excess water } \\
\text { capacity; maximum energy production. }\end{array}$ & [79] \\
\hline
\end{tabular}


Table 4. Cont

\begin{tabular}{|c|c|c|c|c|}
\hline Case Study & Limitation of Parameters & Optimization Techniques & Consideration of Main Goal & Ref. \\
\hline Jinsha River, China & $\begin{array}{l}\text { balance, level, head, and outflow of water; hydraulic } \\
\text { connection; storage reservoir. }\end{array}$ & Multi-population ant colony optimization & $\begin{array}{l}\text { The maximum utility of energy production of big } \\
\text { cascaded hydropower plants. }\end{array}$ & [80] \\
\hline Three Gorges, China & $\begin{array}{l}\text { Hydraulic connection; output limit; water limits of } \\
\text { balance, release, level, and reservoir. }\end{array}$ & An adaptive artificial bee colony algorithm & $\begin{array}{l}\text { Maximize the gross utilities of energy production by } \\
\text { finding the optimal procedure of the water level rate. }\end{array}$ & [81] \\
\hline Three Gorges Dam, China & $\begin{array}{l}\text { Hydraulic connection; level, release, and dynamic } \\
\text { balance of water; reservoir water level; output power. }\end{array}$ & Multi-objective artificial bee colony algorithm & $\begin{array}{l}\text { Optimize both generation benefits and firm output } \\
\text { simultaneously. }\end{array}$ & [82] \\
\hline Southeast river, Brazil & $\begin{array}{l}\text { Net head of water storage as a non-linear function, } \\
\text { spillage, and inflow. }\end{array}$ & Predictive control & $\begin{array}{c}\text { To exemplify hydro energy production by using } \\
\text { deterministic optimization model. }\end{array}$ & [83] \\
\hline Paranaíba River, Brazil & $\begin{array}{l}\text { Net head of water storage as a non-linear function, } \\
\text { spillage, and inflow. }\end{array}$ & Predictive control & $\begin{array}{l}\text { Provide an inflow sequence and supply the optimal } \\
\text { inflow solutions throughout a specific period. }\end{array}$ & [84] \\
\hline UNICAMP, Brazil & $\begin{array}{l}\text { Operating costs; generation; head and discharge of } \\
\text { water; release and balance of the reservoir; spillage. }\end{array}$ & Adaptive model predictive control & $\begin{array}{l}\text { Provides optimal releases and optimizes operation } \\
\text { costs plus the minimum future operation costs. }\end{array}$ & [85] \\
\hline Block diagram & $\begin{array}{l}\text { The capacity of the reservoir; minimum and maximum } \\
\text { for storage and discharge. }\end{array}$ & Tabu search algorithm & $\begin{array}{l}\text { Predictable value of the water residual in the reservoir, } \\
\text { optimize power generated, and water conservation. }\end{array}$ & {$[86,87]$} \\
\hline Spain & $\begin{array}{l}\text { Independent, linear and quadratic coefficients, and the } \\
\text { predicted value operator of the probabilistic production } \\
\text { expenses; generation; the flow per specific commodity }\end{array}$ & The non-linear network flow technique & $\begin{array}{l}\text { Minimizing the total predictable production expenses } \\
\text { per period, considering the water inflows per period. }\end{array}$ & [88] \\
\hline Norway & $\begin{array}{l}\text { Maximum and time of generation: minimum and } \\
\text { maximum level of the reservoir; spillage; the value } \\
\text { of storage. }\end{array}$ & Successive linear programming & $\begin{array}{l}\text { How is scheduling mixed in the new arrangement for } \\
\text { market-clearing and system operation? }\end{array}$ & [89] \\
\hline Leirdøla, Norway & $\begin{array}{l}\text { Volume available capacity of bid; water flow rate; } \\
\text { generated power; the day-ahead; balance, level, and } \\
\text { bounds of the reservoir; start-up and shutdown costs. }\end{array}$ & $\begin{array}{l}\text { The multistage stochastic mixed-integer } \\
\text { programming model }\end{array}$ & $\begin{array}{l}\text { Generate bid curves as this is the only output that } \\
\text { depends on the expectation on future prices rather } \\
\text { than the actual realizations. }\end{array}$ & [90] \\
\hline Nord Pool, Norway & $\begin{array}{l}\text { Min and max level, production, spillage, and Inflow of } \\
\text { reservoir; electricity price; water discharge. }\end{array}$ & Linear Decision Rules & $\begin{array}{l}\text { Obtain optimal use of resources and the expected } \\
\text { discounted market value of total production. }\end{array}$ & [91] \\
\hline Miño-Sil River, Spain & $\begin{array}{l}\text { Hourly water inflows and head; reservoir level; } \\
\text { generation; costs of wear and tear, start-up/shut-down, } \\
\text { and energy; environmental flows; ramping rates. }\end{array}$ & Mixed-integerlinear programming & $\begin{array}{l}\text { The uninterruptible discharge between sequential } \\
\text { weeks is warranted via accreditation of the inflows per } \\
\text { hour as a variable in the yearly problem. }\end{array}$ & [92] \\
\hline Southern, China & $\begin{array}{l}\text { Electrical energy balance; interruptible load; generating; } \\
\text { head, flow, storage, and balance of water. }\end{array}$ & Mixed-integer programming method & $\begin{array}{l}\text { Minimize the cost caused by various power } \\
\text { interruption measures. }\end{array}$ & [93] \\
\hline Kashmir and Jammu, India & $\begin{array}{l}\text { Average power production; specific weight, flow, and } \\
\text { net head of water; efficiency of turbine and generator. }\end{array}$ & Decision support system & $\begin{array}{l}\text { Improve operational efficiency and make optimal } \\
\text { operational and trading decisions. }\end{array}$ & [94] \\
\hline Three Gorges, China & $\begin{array}{l}\text { One/two-period formulation depends on single-period } \\
\text { utility includes (reservoir volume storage; inflow and } \\
\text { release of water) and maximum cumulative utility. }\end{array}$ & Marginal utility principle & $\begin{array}{l}\text { Determine the optimal delay of storage among } \\
\text { intervals that set the proposed concept in } \\
\text { water equipping. }\end{array}$ & [95] \\
\hline Francisco River, Brazil & $\begin{array}{l}\text { Storage, spillage, and discharge of water; } \\
\text { upstream plant. }\end{array}$ & Simulation model & $\begin{array}{l}\text { Evaluating the simulation efficiency of the } \\
\text { hydropower model. }\end{array}$ & [96] \\
\hline
\end{tabular}




\section{Conclusions}

The optimal generation scheduling (OGS) of the hydro system is resolved by the employment of various optimization algorithms, which include the heuristic optimization approaches. The description of the objective function of the LMSTHS optimization problem shows the numerous parities and disparities related to hydro generation systems. A renewed and complete survey of the optimization method implementation for the hydro scheduling solution is given in this article, which examines approaches from various perspectives. In this article, the fundamentals of various optimization algorithms for solving the hydro scheduling problem are studied, and special parameters of the algorithms are included. Many methods take into account the statistical analysis of the acquired solutions of the OGS of hydro units, in which several case studies are considered. The article, which describes various optimization approaches to the hydro scheduling problem, considers the qualitative and statistical comparison of the approaches. It may considerably benefit the academic authors in the field of solving the LMSTHS problem limited by the execution of optimization approaches. The solution to the OGS of hydro and thermal systems in alternating current power flow is a more practical problem that may be presented as future research in the field. The scheduling of hydro systems would be more necessary and valuable by considering other sustainable energy resources like wind and solar power, which are currently manipulated by the employment of optimization approaches. The impact of pumped water storage on the solution of LMSTHS problem has additional study potential, which may be investigated in future work.

Author Contributions: Conceptualization, A.T.H. and M.H.S.; Methodology, O.I.A. and N.M.K.; Resources, A.T.H., O.I.A., N.M.K., and S.S.G.; Data Curation, Y.A.A.-J., R.A.A. and S.S.G.; Writing-Original Draft Preparation, A.T.H., S.A.M., and N.M.K.; Writing-Review \& Editing, S.A.M., M.H.S., and N.M.K.; Visualization, B.A.K., and N.M.K.; Supervision, M.H.S.; Funding Acquisition, S.A.M., and N.M.K. All authors have read and agreed to the published version of the manuscript.

Acknowledgments: The authors like to express their sincere gratitude to the Universiti Malaysia Pahang, Pekan, Pahang, Malaysia, Universiti Tenaga Nasional, Kajang, Selangor, Malaysia and Universiti Tun Hussein Onn Malaysia (UTHM), Batu Pahat, Johor, Malaysia for providing technical inputs.

Conflicts of Interest: The authors declare no conflict of interest.

\section{References}

1. Yah, N.F.; Oumer, A.N.; Idris, M.S. Small scale hydro-power as a source of renewable energy in Malaysia: A review. Renew. Sustain. Energy Rev. 2017, 72, 228-239. [CrossRef]

2. Jamil, R.; Jamil, I.; Jinquan, Z.; Li, M.; Qirong, J.; Jamil, R. Development Trend of Chinese Hydroelectric Generation Technology of Hydro Power Plant (HPP). Int. J. Eng. Works Kambohwell Publ. Enterp. 2014, 1, 1-5.

3. Binama, M.; Su, W.T.; Li, X.B.; Li, F.C.; Wei, X.Z.; An, S. Investigation on pump as turbine (PAT) technical aspects for micro hydropower schemes: A state-of-the-art review. Renew. Sustain. Energy Rev. 2017, 79, 148-179. [CrossRef]

4. Martínez-Lucas, G.; Sarasúa, J.I.; Sánchez-Fernández, J.Á. Frequency regulation of a hybrid wind-hydro power plant in an isolated power system. Energies 2018, 11, 239. [CrossRef]

5. Hammid, A.T.; Sulaiman, M.H.B.; Awad, O.I. A Robust firefly algorithm with backpropagation neural networks for solving hydrogeneration prediction. Electr. Eng. 2018, 100, 2617-2633. [CrossRef]

6. Nazari-Heris, M.; Mohammadi-Ivatloo, B.; Gharehpetian, G. Short-term scheduling of hydro-based power plants considering application of heuristic algorithms: A comprehensive review. Renew. Sustain. Energy Rev. 2017, 74, 116-129. [CrossRef]

7. Kumar, A.; Wu, G.; Ali, M.Z.; Mallipeddi, R.; Suganthan, P.N.; Das, S. A test-suite of non-convex constrained optimization problems from the real-world and some baseline results. Swarm Evol. Comput. 2020, 56, 100693. [CrossRef]

8. Kaboli, S.H.A.; Alqallaf, A.K. Solving non-convex economic load dispatch problem via artificial cooperative search algorithm. Expert Syst. Appl. 2019, 128, 14-27. [CrossRef]

9. Ramos-Real, F.J.; Barrera-Santana, J.; Ramírez-Díaz, A.; Perez, Y. Interconnecting isolated electrical systems. The case of Canary Islands. Energy Strategy Rev. 2018, 22, 37-46. [CrossRef] 
10. Pérez-Díaz, J.I.; Wilhelmi, J.R. Assessment of the economic impact of environmental constraints on short-term hydropower plant operation. Energy Policy 2010, 38, 7960-7970. [CrossRef]

11. Wang, L.; Wang, B.; Zhang, P.; Liu, M.; Li, C. Study on optimization of the short-term operation of cascade hydropower stations by considering output error. J. Hydrol. 2017, 549, 326-339. [CrossRef]

12. Bignucolo, F.; Caldon, R.; Coppo, M.; Pasut, F.; Pettinà, M. Integration of lithium-ion battery storage systems in hydroelectric plants for supplying primary control reserve. Energies 2017, 10, 98. [CrossRef]

13. Cordova, M.M.; Finardi, E.C.; Ribas, F.A.C.; de Matos, V.L.; Scuzziato, M.R. Performance evaluation and energy production optimization in the real-time operation of hydropower plants. Electr. Power Syst. Res. 2014, 116, 201-207. [CrossRef]

14. Chang, J.; Li, Y.; Yuan, M.; Wang, Y. Efficiency evaluation of hydropower station operation: A case study of Longyangxia station in the Yellow River, China. Energy 2017, 35, 23-31. [CrossRef]

15. Brekke, J.K. Medium-term Hydropower Scheduling with Provision of Capacity Reserves and Inertia. In Proceedings of the IEEE 2016 51st International Universities Power Engineering Conference (UPEC), Coimbra, Portugal, 6-9 September 2016; NTNU: Trondheim, Norway, 2016.

16. Feng, Z.K.; Niu, W.J.; Cheng, C.T.; Wu, X.Y. Optimization of hydropower system operation by uniform dynamic programming for dimensionality reduction. Energy 2017, 134, 718-730. [CrossRef]

17. Guisández, I.; Pérez-Díaz, J.I.; Wilhelmi, J.R. Assessment of the economic impact of environmental constraints on annual hydropower plant operation. Energy Policy 2013, 61, 1332-1343. [CrossRef]

18. Zhang, X.; Yu, X.; Qin, H. Optimal operation of multi-reservoir hydropower systems using enhanced comprehensive learning particle swarm optimization. J. Hydro-Environ. Res. 2016, 10, 50-63. [CrossRef]

19. Garcia, M.; Nagarajan, H.; Baldick, R. Generalized Convex Hull Pricing for the AC Optimal Power Flow Problem. IEEE Trans. Control Netw. Syst. 2020. [CrossRef]

20. Yang, T.; Gao, X.; Sellars, S.L.; Sorooshian, S. Improving the multi-objective evolutionary optimization algorithm for hydropower reservoir operations in the California Oroville-Thermalito complex. Environ. Model. Softw. 2015, 69, 262-279. [CrossRef]

21. Mostafa, S.A.; Mustapha, A.; Mohammed, M.A.; Ahmad, M.S.; Mahmoud, M.A. A fuzzy logic control in adjustable autonomy of a multi-agent system for an automated elderly movement monitoring application. Int. J. Med. Inform. 2018, 112, 173-184. [CrossRef]

22. Jaber, S.; Chen, W.; Wang, K.; Li, J. Subcarrier Assignment and Power Allocation for SCMA Energy Efficiency. arXiv 2020, arXiv:2004.09960.

23. Iliadis, N.A.; Gnansounou, E. Development of the methodology for the evaluation of a hydro-pumped storage power plant: Swiss case study. Energy Strategy Rev. 2016, 9, 8-17. [CrossRef]

24. Ge, X.L.; Zhang, L.Z.; Shu, J.; Xu, N.F. Short-term hydropower optimal scheduling considering the optimization of water time delay. Electr. Power Syst. Res. 2014, 110, 188-197. [CrossRef]

25. Catalão, J.P.D.S.; Pousinho, H.M.I.; Mendes, V.M.F. Mixed-integer non-linear approach for the optimal scheduling of a head-dependent hydro chain. Electr. Power Syst. Res. 2010, 80, 935-942. [CrossRef]

26. Catalão, J.P.D.S.; Pousinho, H.M.I.; Mendes, V.M.F. Scheduling of head-dependent cascaded hydro systems: Mixed-integer quadratic programming approach. Energy Convers. Manag. 2010, 51, 524-530. [CrossRef]

27. Catalão, J.P.S.; Mariano, S.J.P.S.; Mendes, V.M.F.; Ferreira, L.A.F.M. Scheduling of head-sensitive cascaded hydro systems: A non-linear approach. IEEE Trans. Power Syst. 2008, 24, 337-346. [CrossRef]

28. Belsnes, M.M.; Wolfgang, O.; Follestad, T.; Aasgård, E.K. Applying successive linear programming for stochastic short-term hydropower optimization. Electr. Power Syst. Res. 2016, 130, 167-180. [CrossRef]

29. Ge, X.; Xia, S.; Lee, W.J.; Chung, C.Y. A successive approximation approach for short-term cascaded hydro scheduling with variable water flow delay. Electr. Power Syst. Res. 2018, 154, 213-222. [CrossRef]

30. Ma, C.; Lian, J.; Wang, J. Short-term optimal operation of Three-gorge and Gezhouba cascade hydropower stations in non-flood season with operation rules from data mining. Energy Convers. Manag. 2013, 65, 616-627. [CrossRef]

31. Mo, L.; Lu, P.; Wang, C.; Zhou, J. Short-term hydro generation scheduling of Three Gorges-Gezhouba cascaded hydropower plants using hybrid MACS-ADE approach. Energy Convers. Manag. 2013, 76, 260-273. [CrossRef]

32. Glotić, A.; Glotić, A.; Kitak, P.; Pihler, J.; Tičar, I. Parallel self-adaptive differential evolution algorithm for solving short-term hydro scheduling problem. IEEE Trans. Power Syst. 2014, 29, 2347-2358. [CrossRef] 
33. Yuan, X.; Yuan, Y.; Zhang, Y. A hybrid chaotic genetic algorithm for short-term hydro system scheduling. Math. Comput. Simul. 2002, 59, 319-327. [CrossRef]

34. Chuanwen, J.; Bompard, E. A self-adaptive chaotic particle swarm algorithm for short term hydroelectric system scheduling in deregulated environment. Energy Convers. Manag. 2005, 46, 2689-2696. [CrossRef]

35. Li, G.; Sun, Y.; He, Y.; Li, X.; Tu, Q. Short-term power generation energy forecasting model for small hydropower stations using GA-SVM. Math. Probl. Eng. 2014, 2014, 381387. [CrossRef]

36. Mu, J.; Ma, C.; Zhao, J.; Lian, J. Optimal operation rules of Three-gorge and Gezhouba cascade hydropower stations in flood season. Energy Convers. Manag. 2015, 96, 159-174. [CrossRef]

37. Séguin, S.; Côté, P.; Audet, C. Self-scheduling short-term unit commitment and loading problem. IEEE Trans. Power Syst. 2016, 31, 133-142. [CrossRef]

38. Yuan, L.; Zhou, J. Self-optimization system dynamics simulation of real-time short term cascade hydropower system considering uncertainties. Water Resour. Manag. 2017, 31, 2127-2140. [CrossRef]

39. Ji, C.; Li, C.; Wang, B.; Liu, M.; Wang, L. Multi-stage dynamic programming method for short-term cascade reservoirs optimal operation with flow attenuation. Water Resour. Manag. 2017, 31, 4571-4586. [CrossRef]

40. Jiekang, W.; Zhuangzhi, G.; Fan, W. Short-term multi-objective optimization scheduling for cascaded hydroelectric plants with dynamic generation flow limit based on EMA and DEA. Int. J. Electr. Power Energy Syst. 2014, 57, 189-197. [CrossRef]

41. Wu, X.Y.; Cheng, C.T.; Shen, J.J.; Luo, B.; Liao, S.L.; Li, G. A multi-objective short term hydropower scheduling model for peak shaving. Int. J. Electr. Power Energy Syst. 2015, 68, 278-293. [CrossRef]

42. Lu, P.; Zhou, J.; Wang, C.; Qiao, Q.; Mo, L. Short-term hydro generation scheduling of Xiluodu and Xiangjiaba cascade hydropower stations using improved binary-real coded bee colony optimization algorithm. Energy Convers. Manag. 2015, 91, 19-31. [CrossRef]

43. Marchand, A.; Gendreau, M.; Blais, M.; Emiel, G. Fast near-optimal heuristic for the short-term hydro-generation planning problem. IEEE Trans. Power Syst. 2017, 33, 227-235. [CrossRef]

44. Aasgård, E.K.; Naversen, C.Ø.; Fodstad, M.; Skjelbred, H.I. Optimizing day-ahead bid curves in hydropower production. Energy Syst. 2018, 9, 257-275. [CrossRef]

45. Naresh, R.; Sharma, J. Short term hydro scheduling using two-phase neural network. Int. J. Electr. Power Energy Syst. 2002, 24, 583-590. [CrossRef]

46. Xu, B.; Zhong, P.A.; Stanko, Z.; Zhao, Y.; Yeh, W.W.G. A multiobjective short-term optimal operation model for a cascade system of reservoirs considering the impact on long-term energy production. Water Resour. Res. 2015, 51, 3353-3369. [CrossRef]

47. Castro, M.S.; Sousa, J.; Saraiva, J. Hydro scheduling optimization considering the impact on market prices and head drop using the linprog function of MATLAB ${ }^{\circledR}$. In Proceedings of the 2017 IEEE Manchester PowerTech, Manchester, UK, 18-22 June 2017.

48. Xie, M.; Zhou, J.; Li, C.; Lu, P. Daily generation scheduling of cascade hydro plants considering peak shaving constraints. J. Water Resour. Plan. Manag. 2016, 142, 04015072. [CrossRef]

49. Yuan, X.; Zhang, Y.; Wang, L.; Yuan, Y. An enhanced differential evolution algorithm for daily optimal hydro generation scheduling. Comput. Math. Appl. 2008, 55, 2458-2468. [CrossRef]

50. Yuan, X.; Wang, L.; Yuan, Y. Application of enhanced PSO approach to optimal scheduling of hydro system. Energy Convers. Manag. 2008, 49, 2966-2972. [CrossRef]

51. Moreno, S.R.; Kaviski, E. Daily Scheduling of Small Hydro Power Plants Dispatch With Modified Particles Swarm Optimization. Pesqui. Oper. 2015, 35, 25-37. [CrossRef]

52. Shrestha, G.B.; Pokharel, B.K.; Lie, T.T.; Fleten, S.E. Medium term power planning with bilateral contracts. IEEE Trans. Power Syst. 2005, 20, 627-633. [CrossRef]

53. Baslis, C.G.; Bakirtzis, A.G. Mid-term stochastic scheduling of a price-maker hydro producer with pumped storage. IEEE Trans. Power Syst. 2011, 26, 1856-1865. [CrossRef]

54. Catalão, J.; Pousinho, H.; Contreras, J. Optimal hydro scheduling and offering strategies considering price uncertainty and risk management. Energy 2012, 37, 237-244. [CrossRef]

55. Flatabø, N.; Haugstad, A.; Mo, B.; Fosso, O.B. Short-term and medium-term generation scheduling in the Norwegian hydro system under a competitive power market structure. In Proceedings of the EPSOM'98 (International Conference on Electrical Power System Operation and Management), ETH Zürich, Switzerland, 23-25 September 1998. 
56. Abgottspon, H.; Bucher, M.; Andersson, G. Stochastic dynamic programming for unified short-and medium-term planning of hydro power considering market products. In Proceedings of the 12th IEEE International Conference on Probabilistic Methods Applied to Power Systems (PMAPS), Istanbul, Turkey, 10-14 June 2012.

57. Abgottspon, H.; Andersson, G. Approach of integrating ancillary services into a medium-term hydro optimization. In Proceedings of the XII SEPOPE: Symposium of Specialists in Electric Operational and Expansion Planning, Zurich, Switzerland, 20-23 May 2012.

58. Abgottspon, H.; Njálsson, K.; Bucher, M.A.; Andersson, G. Risk-averse medium-term hydro optimization considering provision of spinning reserves. In Proceedings of the IEEE 2014 International Conference on Probabilistic Methods Applied to Power Systems, Durham, UK, 7-10 July 2014; pp. 1-6.

59. Helseth, A.; Fodstad, M.; Mo, B. Optimal medium-term hydropower scheduling considering energy and reserve capacity markets. IEEE Trans. Sustain. Energy 2016, 7, 934-942. [CrossRef]

60. Hjelmeland, M.N.; Helseth, A.; Korpås, M. A case study on medium-term hydropower scheduling with sales of capacity. Energy Procedia 2016, 87, 124-131. [CrossRef]

61. Aquino, R.R.; Carvalho, M.A.; Neto, O.N.; Lira, M.M.; de Almeida, G.J.; Tiburcio, S.N. Recurrent neural networks solving a real large scale mid-term scheduling for power plants. In Proceedings of the IEEE the 2010 International Joint Conference on Neural Networks (IJCNN), Barcelona, Spain, 18-23 July 2010; pp. 1-6.

62. Aquino, R.R.; Neto, O.N.; Lira, M.M.; Carvalho, M.A. Solving a real large scale mid-term scheduling for power plants via hybrid intelligent neural networks systems. In Proceedings of the IEEE 2011 International Joint Conference on Neural Networks, San Jose, CA, USA, 31 July-5 August 2011; pp. 785-792.

63. Lotfi, M.; Ghaderi, S. Possibilistic programming approach for mid-term electric power planning in deregulated markets. Int. J. Electr. Power Energy Syst. 2012, 34, 161-170. [CrossRef]

64. Zhao, Y.; Chen, X.; Jia, Q.S.; Guan, X.; Zhang, S.; Jiang, Y. Long-term scheduling for cascaded hydro energy systems with annual water consumption and release constraints. IEEE Trans. Autom. Sci. Eng. 2010, 7, 969-976. [CrossRef]

65. Scarcelli, R.O.; Zambelli, M.S.; Filho, S.; Carneiro, A.A. Aggregated inflows on stochastic dynamic programming for long term hydropower scheduling. In Proceedings of the IEEE 2014 North American Power Symposium, Pullman, WA, USA, 7-9 September 2014; pp. 1-6.

66. Scarcelli, R.O.C.; Zambelli, M.S.; Soares, S.; Carneiro, A.A. Ensemble of Markovian stochastic dynamic programming models in different time scales for long term hydropower scheduling. Electr. Power Syst. Res. 2017, 150, 129-136. [CrossRef]

67. Mo, B.; Gjelsvik, A.; Grundt, A. Integrated risk management of hydro power scheduling and contract management. IEEE Trans. Power Syst. 2001, 16, 216-221. [CrossRef]

68. Mo, B.; Gjelsvik, A.; Grundt, A.; Karesen, K. Optimisation of hydropower operation in a liberalised market with focus on price modelling. In Proceedings of the 2001 IEEE Porto Power Tech Proceedings, Porto, Portugal, 10-13 September 2001; p. 6.

69. Hongling, L.; Chuanwen, J.; Yan, Z. A review on risk-constrained hydropower scheduling in deregulated power market. Renew. Sustain. Energy Rev. 2008, 12, 1465-1475. [CrossRef]

70. Larsen, C.T.; Doorman, G.L.; Mo, B. Evaluation of scenario reduction methods for stochastic inflow in hydro scheduling models. In Proceedings of the 2015 IEEE Eindhoven PowerTech, Eindhoven, The Netherlands, 29 June-2 July 2015.

71. Hjelmeland, M.N.; Korpås, M.; Helseth, A. Combined SDDP and simulator model for hydropower scheduling with sales of capacity. In Proceedings of the IEEE 2016 13th International Conference on the European Energy Market, Porto, Portugal, 6-9 June 2016.

72. Lu, B.; Li, K.; Zhang, H.; Wang, W.; Gu, H. Study on the optimal hydropower generation of Zhelin reservoir. J. Hydro-Environ. Res. 2013, 7, 270-278. [CrossRef]

73. Xie, M.; Zhou, J.; Li, C.; Zhu, S. Long-term generation scheduling of Xiluodu and Xiangjiaba cascade hydro plants considering monthly streamflow forecasting error. Energy Convers. Manag. 2015, 105, 368-376. [CrossRef]

74. Cheng, C.T.; Wang, W.C.; Xu, D.M.; Chau, K.W. Optimizing hydropower reservoir operation using hybrid genetic algorithm and chaos. Water Resour. Manag. 2008, 22, 895-909. [CrossRef] 
75. He, Y.Y.; Zhou, J.Z.; Xiang, X.Q.; Chen, H.; Qin, H. Comparison of different chaotic maps in particle swarm optimization algorithm for long-term cascaded hydroelectric system scheduling. Chaos Solitons Fractals 2009, 42, 3169-3176. [CrossRef]

76. Hammid, A.T.; Sulaiman, M.H. Optimal Long-Term Hydro Generation Scheduling of Small Hydropower Plant (SHP) using Metaheuristic Algorithm in Himreen Lake Dam. In Proceedings of the MATEC Web of Conferences, Kuala Lumpur, Malaysia, 28-30 November 2017.

77. Hammid, A.T.; Sulaiman, M.H.B. Series division method based on PSO and FA to optimize Long-Term Hydro Generation Scheduling. Sustain. Energy Technol. Assess. 2018, 29, 106-118. [CrossRef]

78. Liao, S.L.; Liu, B.X.; Cheng, C.T.; Li, Z.F.; Wu, X.Y. Long-term generation scheduling of hydropower system using multi-core parallelization of particle swarm optimization. Water Resour. Manag. 2017, 31, 2791-2807. [CrossRef]

79. Zhang, H.; Zhou, J.; Fang, N.; Zhang, R.; Zhang, Y. An efficient multi-objective adaptive differential evolution with chaotic neuron network and its application on long-term hydropower operation with considering ecological environment problem. Int. J. Electr. Power Energy Syst. 2013, 45, 60-70. [CrossRef]

80. Wang, C.; Zhou, J.; Lu, P.; Yuan, L. Long-term scheduling of large cascade hydropower stations in Jinsha River, China. Energy Convers. Manag. 2015, 90, 476-487. [CrossRef]

81. Liao, X.; Zhou, J.; Zhang, R.; Zhang, Y. An adaptive artificial bee colony algorithm for long-term economic dispatch in cascaded hydropower systems. Int. J. Electr. Power Energy Syst. 2012, 43, 1340-1345. [CrossRef]

82. Liao, X.; Zhou, J.; Ouyang, S.; Zhang, R.; Zhang, Y. Multi-objective artificial bee colony algorithm for long-term scheduling of hydropower system: A case study of china. Water Util. J. 2014, 7, 13-23.

83. Zambelli, M.S.; Luna, I.; Soares, S. Predictive Control Approach for Long-Term Hydropower Scheduling Using Annual Inflow Forecasting Model. IFAC Proc. Vol. 2009, 42, 191-196. [CrossRef]

84. Zambelli, M.S.; Luna, I.; Soares, S. Long-term hydropower scheduling based on deterministic non-linear optimization and annual inflow forecasting models. In Proceedings of the 2009 IEEE Bucharest PowerTech, Bucharest, Romania, 28 June-2 July 2009; pp. 1-8.

85. Zambelli, M.; Soares Filho, S.; Toscano, A.E.; Santos, E.D.; Silva Filho, D.D. NEWAVE versus ODIN: Comparison of stochastic and deterministic models for the long term hydropower scheduling of the interconnected brazilian system. Sba Controle Automação Soc. Bras. Autom. 2011, 22, 598-609. [CrossRef]

86. Mantawy, A.; Soliman, S.; El-Hawary, M. A new tabu search algorithm for the long-term hydro scheduling problem. In Proceedings of the IEEE Power Engineering 2002 Large Engineering Systems Conference on LESCOPE 02, Halifax, NS, Canada, 26-28 June 2002.

87. Mantawy, A.H.; Soliman, S.A.; El-Hawary, M.E. The long-term hydro-scheduling problem-A new algorithm. Electr. Power Syst. Res. 2003, 64, 67-72. [CrossRef]

88. Nabona, N. Multicommodity network flow model for long-term hydro-generation optimization. IEEE Trans. Power Syst. 1993, 8, 395-404. [CrossRef]

89. Fosso, O.B.; Gjelsvik, A.; Haugstad, A.; Mo, B.; Wangensteen, I. Generation scheduling in a deregulated system. The Norwegian case. IEEE Trans. Power Syst. 1999, 14, 75-81. [CrossRef]

90. Fleten, S.E.; Haugstvedt, D.; Steinsbø, J.A.; Belsnes, M.; Fleischmann, F. Bidding Hydropower Generation: Integrating Short-and Long-Term Scheduling; University Library of Munich: Munich, Germany, 2011.

91. Grønvik, I.; Hadziomerovic, A.; Ingvoldstad, N.; Egging, R.; Fleten, S.E. Feasibility of linear decision rules for hydropower scheduling. In Proceedings of the IEEE 2014 International Conference on Probabilistic Methods Applied to Power Systems (PMAPS), Durham, UK, 7-10 July 2014; pp. 1-6.

92. Guisández, I.; Pérez-Díaz, J.; Wilhelmi, J. Effects of the maximum flow ramping rates on the long-term operation decisions of a hydropower plant. In Proceedings of the International Conference on Renewable Energies and Power Quality, Córdoba, Spain, 7-10 April 2014.

93. Ge, X.; Zhong, J.; Xia, S. Long-term scheduling with the consideration of interruptible load. In Proceedings of the 2016 IEEE International Conference on Power and Renewable Energy (ICPRE), Shanghai, China, 21-23 October 2016.

94. Sharma, R.N.; Chand, N.; Sharma, V.; Yadav, D. Decision support system for operation, scheduling and optimization of hydro power plant in Jammu and Kashmir region. Renew. Sustain. Energy Rev. 2015, 43, 1099-1113. [CrossRef] 
95. Zhao, T.; Zhao, J.; Liu, P.; Lei, X. Evaluating the marginal utility principle for long-term hydropower scheduling. Energy Convers. Manag. 2015, 106, 213-223. [CrossRef]

96. Xiomara, B.; Soares, S. Accuracy assessment of the long-term hydro simulation model used in Brazil based on post-operation data. In Proceedings of the IEEE 2017 6th International Conference on Clean Electrical Power (ICCEP), Santa Margherita Ligure, Italy, 27-29 June 2017. 